\title{
Corporate Governance, Capital Expenditure Dan Cash Holdings
}

\author{
Yanti, Liana Susanto, Henny Wirianata, Viriany \\ Fakultas Ekonomi, Universitas Tarumanagara, Jakarta \\ yanti@fe.untar.ac.id
}

\begin{abstract}
This study aims to obtain empirical evidence about the effect of Corporate Governance and Capital Expenditure on Cash Holding. This study use secondary data from financial statements of manufacturing companies listed on the Indonesia Stock Exchange in 2014-2016. The structure of Corporate Governance is measured using independent commissioners, board of commissioners, and institutional ownership. The analytical method used in this study is multiple regression analysis which is processed with the E-Views program. The results of this study indicate that independent commissioners, board size, and institutional ownership partially have no significant effect on cash holding. While Capital Expenditure has a significant and negative effect on cash holding.
\end{abstract}

Keywords: Corporate Governance, Capital Expenditure, Cash Holdings.

Abstrak: Penelitian ini bertujuan untuk memperoleh bukti empiris mengenai pengaruh Corporate Governance dan Capital Expenditure terhadap Cash Holding. Data penelitian bersumber dari laporan keuangan perusahaan manufaktur yang terdaftar di Bursa Efek Indonesia tahun 2014-2016. Struktur Corporate Governance diukur menggunakan komisaris independen, dewan komisaris, dan kepemilikan institusional. Metode analisis yang digunakan adalah analisis regresi berganda yang diolah dengan program E-Views. Hasil penelitian menunjukkan bahwa komisaris independen, ukuran dewan komisaris, dan kepemilikan institusional secara parsial tidak berpengaruh signifikan terhadap cash holdings. Sedangkan Capital Expenditure berpengaruh signifikan dan negatif terhadap cash holding.

Kata Kunci: Corporate Governance, Capital Expenditure, Cash Holdings.

\section{PENDAHULUAN}

Kebijakan perusahaan dalam menentukan jumlah persediaan uang tunai akan menentukan kebijakan keuangan suatu perusahaan secara keseluruhan. Hal ini disebabkan karena kas adalah aset yang sangat penting karena akan menentukan keberlangsungan hidup perusahaan. Kas dapat mempengaruhi likuiditas perusahaan dan menunjukkan kemampuan perusahaan memenuhi seluruh kewajibannya tepat waktu. Oleh karena persediaan uang tunai diperlukan dalam membiayai seluruh kegiatan operasional perusahaan, maka perusahaan seringkali memilih untuk menahan sejumlah besar kas untuk menghindari ketidakpastian.

Cash holdings adalah sejumlah uang tunai yang siap digunakan di dalam perusahaan untuk dibelanjakan dalam bentuk membeli asset-aset berwujud dan dibagikan kepada 
investor (Gill dan Shah, 2012). Cash holdings bisa berbentuk uang tunai, uang di bank, dan surat-surat berharga. Menurut (Ferreira dan Vilela, 2004), ada beberapa manfaat bagi perusahaan yang menahan kas. Pertama, cash holdings mengurangi kemungkinan terjadinya financial distress yang diakibatkan karena kondisi ekonomi yang sedang tidak menentu dimana cash holdings menjadi dana cadangan untuk menghindari kebangkrutan. Kedua, cash holdings memungkinkan perusahaan melakukan kebijakan investasi secara lebih optimal karena sebagai sumber dana internal, kas tidak membutuhkan biaya seperti halnya sumber dana eksternal.

Penelitian (Bates et al., 2009) menemukan bahwa perusahaan-perusahaan di Amerika rata-rata rasio kas terhadap total asset meningkat lebih dari dua kali lipat dari tahun 1980 sampai dengan tahun 2006. Mereka menemukan bahwa kenaikan rasio ini disebabkan karena meningkatnya ketidakpastian dalam arus kas perusahaan.

Terdapat penelitian sebelumnya yang menemukan bahwa keputusan para manajer dalam menentukan cash holdings di perusahaan dipengaruhi oleh keberadaan badan pengawas untuk meningkatkan perlindungan terhadap hak pemegang saham minoritas. Hal ini dikenal dengan praktek corporate governance. Corporate Governance bertujuan untuk memastikan agar pihak manajemen tidak bertindak untuk memenuhi kepentingannya sendiri dengan menimbun kas secara berlebihan (Lee and Lee, 2010). Struktur Corporate Governance meliputi komisaris independen, ukuran dewan komisaris, dan kepemilikan institusional.

Keputusan melakukan belanja modal (Capital Expenditure) juga mempengaruhi Cash Holding perusahaan (Sutrisno dan Gumanti, 2016). Semakin besar belanja modal, maka Cash Holding akan menurun, dan sebaliknya apabila belanja modal menurun, maka Cash Holding akan meningkat (Enyew, 2016).

Beberapa penelitian sebelumnya telah dilakukan untuk mengetahui faktor-faktor yang mempengaruhi cash holdings. (Wassiuzzaman, 2014), (Rehman and Wang, 2015), (Rahman and Muhamad, 2013), dan (Kuan et al., 2011) melakukan penelitian tentang tentang pengaruh komisaris independen terhadap cash holding. Mereka menemukan bahwa komisaris independen berpengaruh signifikan dan negatif terhadap cash holdings. Tetapi di pihak lain, (Basheer, 2014) dan (Senjaya dan Yadnyana, 2016) dalam penelitian mereka menemukan sebaliknya dimana komisaris independen tidak berpengaruh secara signifikan terhadap cash holdings.

(Christian dan Fauziah, 2017), (Gill dan Shah, 2012), (Senjaya dan Yadnyana, 2016), (Kuan et al., (2012), (Rehman and Wang, 2015), dan (Jamil et al., 2016) melakukan penelitian tentang pengaruh ukuran dewan komisaris terhadap cash holdings. Mereka menemukan bahwa ukuran dewan komisaris berpengaruh signifikan dan positif terhadap cash holdings. Namun, (Wassiuzzaman, 2014) dalam penelitiannya membuktikan hal yang sebaliknya, yaitu bahwa terdapat pengaruh yang tidak signifikan ukuran dewan komisaris terhadap cash holding.

(Christina dan Ekawati, 2014) dan (Harford et al., 2008) melakukan penelitian tentang pengaruh kepemilikan institusional terhadap cash holdings. (Harford et al., 2008) menemukan bahwa bahwa kepemilikan institusional berpengaruh signifikan dan positif terhadap cash holdings, sedangkan hasil penelitian (Christina dan Ekawati, 2014) menemukan bahwa kepemilikan institusional berpengaruh signifikan dan negatif terhadap cash holdings. Hasil penelitian yang bertolak belakang ditemukan oleh (Senjaya dan Yadnyana, 2016). Mereka menemukan bahwa kepemilikan institusional tidak berpengaruh signifikan terhadap cash holding. 
(Kim et al., 2011), (Rehman and Wang 2015), (Wassiuzzaman, 2014), (Enyew A, 2016), (Bates et al., 2009), dan (Sutrisno dan Gumanti, 2016) melakukan penelitian tentang pengaruh capital expenditure terhadap cash holdings. Mereka menemukan bahwa capital expenditure berpengaruh secara signifikan dan negatif terhadap cash holdings. Sementara (Borhanuddin, 2011) dan (Guney, 2006) dalam penelitian mereka menunjukkan bahwa capital expenditure tidak berpengaruh secara signifikan terhadap cash holdings.

Berdasarkan hasil penelitian yang belum konsisten tersebut, maka penelitian ini dilakukan untuk meneliti lebih lanjut pengaruh unsur-unsur Corporate Governance dan Capital Expenditure terhadap Cash Holdings dengan sampel dan tahun yang berbeda. Salah satu sektor usaha terbesar yang ada di Indonesia yang membutuhkan kas dan setara kas dalam jumlah besar dan merupakan pendorong pertumbuhan ekonomi yang utama di Indonesia adalah sektor manufaktur. Hal ini menjadi alasan utama yang menjadikan sektor ini layak untuk diteliti.

\section{KAJIAN TEORI}

Trade-Off Theory. Menurut (Myers, 1977), tingkat cash holdings yang optimal dapat dicapai dengan menyeimbangkan biaya dan manfaat marjinal terkait dengan cash holdings. Manfaat marjinal dari cash holdings adalah ketika dengan dengan cash holding, perusahaan bisa menghindari financial distress. Cash holdings bertindak sebagai alat untuk menciptakan kebijakan investasi yang optimal.Perusahaan dengan jumlah cash holdings yang besar dapat mengurangi kenaikan biaya keuangan yang diakibatkan oleh penggunaan dana eksternal yang meningkat atau karena melikuidasi asset perusahaan yang ada. Sedangkan biaya marjinal adalah opportunity cost yang berkaitan dengan cash holdings misalnya tingkat pengembalian investasi jangka pendek yang tidak diperoleh karena perusahaan memilih menahan kas.

Pecking Order Theory. Teori ini memandang kas sebagai penyangga antara laba ditahan dan kebutuhan investasi dan tidak ada tingkat kas yang optimal (Myers and Majluf, 1984). Pecking Order Theory lebih menekankan adanya informasi asimetri yang terjadi dalam keputusan pendanaan karena adanya informasi asimetri ini mengakibatkan pendanaan yang menggunakan dana ekternal menjadi mahal dan menyulitkan sehingga perusahaan memilih untuk menggunakan laba ditahan daripada dana eksternal.

Free Cash Flow Theory. Menurut (Jensen, 1986), Free Cash Flow Theory mengatakan dengan jumlah cash holdings yang besar perusahaan bisa meningkatkan asetnya dan meningkatkan mutu pengambilan keputusan. Free Cash Flowadalah kas yang tersisa setelah dikurangi dengan pembiayaan proyek dan kegiatan operasi sehari-hari. Dengan mempunyai jumlah kas yang cukup untuk investasi, perusahaan bisa lebih mudah untuk membuat keputusan investasi yang tepat.

Agency Theory. (Jensen and Meckling, 1976) menjelaskan hubungan keagenan sebagai kontrak dimana satu atau lebih orang yang disebut principals, memberi perintah kepada pihak lain, yang disebut agen (agent) untuk melaksanakan pekerjaan-pekerjaan atas namaprincipals. Agen dianggap bertindak sesuai dengan kepentingan principals apabila ia mempunyai tujuan yang sama untuk memaksimumkan nilai perusahaan. Dengan proporsi kepemilikan yang hanya sebagian dari perusahaan, membuat manajer atau agen cenderung 
bertindak untuk kepentingan pribadi. Hal inilah yang berpotensi menyebabkan timbulnya agency cost. Menurut teori agensi, biaya agensi dapat dikurangi dengan kehadiran kepemilikan saham oleh manajerial. Masalah keagenan merupakan faktor penentu cash holdings dalam perusahaan karena adanya biaya agen akan mempengaruhi tindakan manajer. Manajer yang mempunyai wewenang dan kebebasan lebih dalam perusahaan, cenderung untuk menahan kas lebih banyak.

Cash Holdings. Menurut (Gill and Shah, 2012), cash holdings merupakan persediaan kas di dalam perusahaan yang akan diperlukan untuk membeli aset fisik dan juga untuk dishare kepada para pemegang saham. Menurut (Jamil et al., 2016) cash holding adalah kas dan juga setara kas yang mudah untuk dikonversi menjadi kas. (Bates et al., 2009) menulis bahwa ada empat motif mengapa perusahaan menahan kas, yaitu: motif transaksi, motif berjaga-jaga, motif pajak, dan motif agensi. Sesuai dengan (Jensen, 1986), manajer cenderung menahan kas daripada meningkatkan pengembalian kepada shareholders ketika perusahaan mengalami kesulitan berinvestasi.

Corporate Governance. Tata kelola perusahaan yang baik adalah suatu sistem yang mengatur hubungan dan peran berbagai pemangku kepentingan misalnya: Dewan Komisaris, peran Direksi, dan pemegang saham. Struktur modal dan keputusan cash holdings merupakan sumber konflik utama antara pemegang saham dan manager. Banyak diskusi tentang Corporate Governance berusaha untuk menjawab pertanyaan para manajer dan dampaknya terhadap cash holdings. Mengacu kepada teori agen, para manajer lebih memilih menahan kas daripada membagikan dividen kepada pemegang saham sehingga hal ini menyebabkan masalah agency (Basheer, 2014; Jensen, 1986). Tata kelola perusahaan yang lemah akan mendorong cash holdings yang berlebihan (Basheer, 2014).

Capital Expenditure. Belanja modal (capital expenditure) adalah biaya yang dikeluarkan untuk memperbaiki atau menciptakan aset baru untuk digunakan perusahaan (Kim, et al., 2011). Menurut (Bates et al., 2009) capital expenditure merupakan biaya untuk menciptakan aset untuk dijadikan jaminan sehingga dapat meningkatkan hutang dan mengurangi cash holding. Capital Expenditure adalah pengeluaran yang dapat memberikan manfaat atau keuntungan di masa depan sehingga tidak di perhitungkan sebagai biaya melainkan pengeluaran modal. Berdasarkan uraian tersebut, maka dapat disimpulkan bahwa capital expenditure merupakan biaya yang dikeluarkan untuk memperbaiki atau menciptakan aset untuk digunakan perusahaan sebagai jaminan.

Kaitan Komisaris Independen Terhadap Cash Holdings. Komisaris independen merupakan komisaris yang berasal dari luar perusahaan dimana komisaris independen diharuskan untuk tidak memiliki hubungan dengan direksi maupun pemegang saham (Senjaya dan Yadnyana, 2016). Menurut (Lee and Lee, 2010), perusahaan dengan jumlah komisaris independen yang banyak akan memiliki cash holdings yang rendah karena komisaris independen dapat mengurangi dominasi dari pihak manajemen untuk menahan kas perusahaan yang dapat memberikan keuntungan kepada mereka. Oleh karena itu dewan komisaris independen mempunyai pengaruh yang negatif terhadap cash holdings. Berdasarkan uraian di atas maka pengaruh komisaris independen terhadap cash holdings dapat dihipotesiskan sebagai berikut:

Ha1: Komisaris Independen berpengaruh negatif terhadap Cash Holdings. 
Kaitan Ukuran Dewan Komisaris Terhadap Cash Holdings. Menurut Senjaya dan (Yadnyana, 2016), fungsi dewan komisaris dalam perusahaan adalah untuk melaksanakan fungsi pengawasan terhadap direksi perusahaan. Menurut (Lee and Lee, 2010) perusahaan dengan ukuran dewan komisaris yang kecil diperkirakan memiliki cash holdings yang kecil karena ukuran dewan komisaris yang kecil cenderung lebih efisien dalam pengambilan keputusan. Adanya pengawasan terhadap tindakan manajemen dapat mengurangi tindakan manajemen yang dapat bertindak sesuai kepentingannya sendiri. Jadi ukuran dewan komisaris mempunyai pengaruh yang positif terhadap cash holdings. Berdasarkan uraian di atas maka pengaruh dewan komisaris independen terhadap cash holdings dapat dihipotesiskan sebagai berikut:

Ha2: Ukuran Dewan Komisaris berpengaruh positif terhadap Cash Holdings.

Kaitan Kepemilikan Institusional Terhadap Cash Holdings. Kepemilikan institusional merupakan kepemilikan saham perusahaan oleh institusi atau badan. Kepemilikan institusional berfungsi sebagai pengawas dan pengendali pihak manajemen agar kepentingan shareholders dapat terlindungi (Senjaya dan Yadnyana, 2016). (Christiana dan Ekawati, 2014) menyatakan bahwa transparansi dan kepemilikan institusional berhubungan positif sehingga dengan tingginya tingkat kepemilikan institusional maka tingkat kepemilikan kas akan semakin kecil untuk menghindari excess cash holdings. Dengan demikian, tingkat kepemilikan institusional memiliki pengaruh yang negatif terhadap cash holdings. Berdasarkan uraian di atas maka pengaruh kepemilikan institusional terhadap cash holdings dapat dihipotesiskan sebagai berikut:

Ha3: Kepemilikan institusional berpengaruh negatif terhadap Cash Holdings.

Kaitan Capital Expenditure Terhadap Cash Holdings. Capital Expenditure merupakan cara perusahaan menggunakan kas yang dimilikinya untuk memperoleh aset atau meningkatkan masa manfaat aset yang dimiliki (Sutrisno dan Gumanti, 2016). Adanya Capital Expenditure akan mempengaruhi besarnya Cash Holding di perusahaan. Dalam penelitian (Sutrisno dan Gumanti, 2016), mereka menemukan bahwa Capital Expenditure berpengaruh negatif terhadap Cash Holding. Pengaruh negatif Capital Expenditure terhadap Cash Holding juga ditemukan dalam penelitian yang dilakukan oleh (Enyew, 2016).

Ha4: Capital Expenditure berpengaruh negatif terhadap Cash Holdings.

Model Penelitian. Model penelitian dapat digambarkan sebagai berikut:

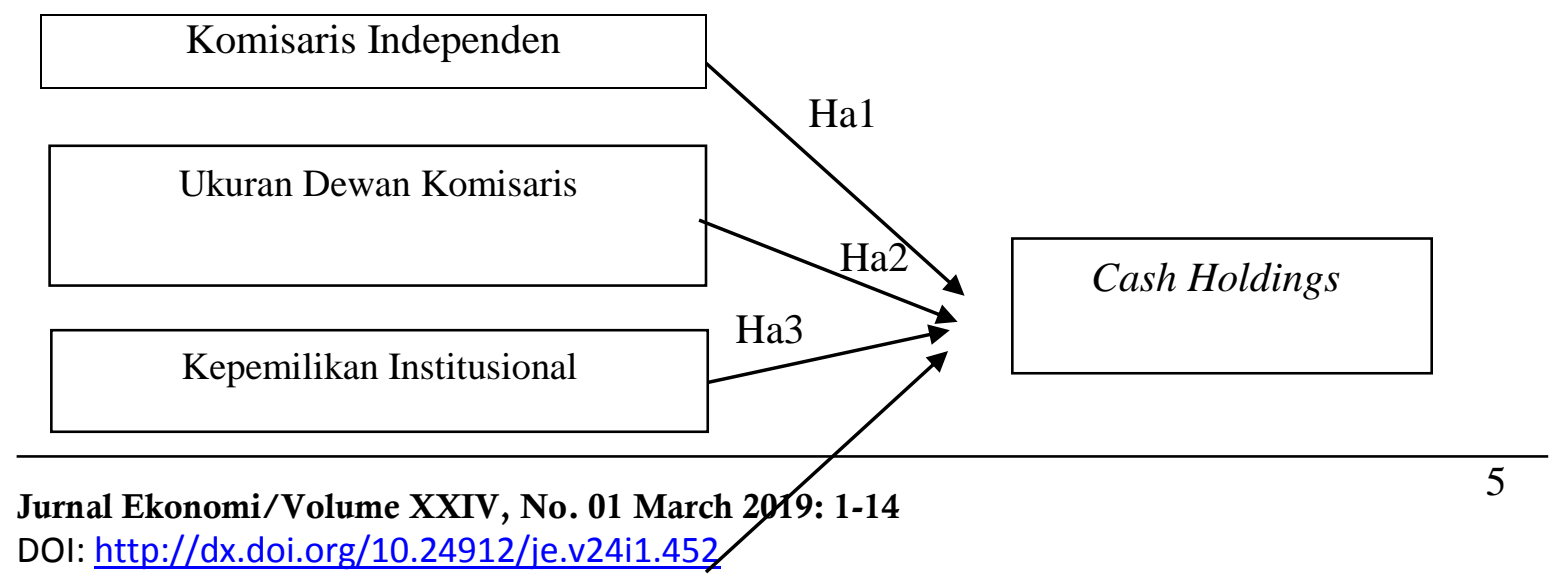


Gambar 1. Model Penelitian

\section{METODE}

Populasi dan Sampel. Populasi penelitian ini adalah seluruh perusahaan manufaktur yang terdaftar di Bursa Efek Indonesia (BEI) tahun 2014-2016. Kriteria pemilihan sampel adalah: (1) Terdaftar di BEI secara konsisten selama 2014-2016; (2) Memiliki data yang lengkap terkait dengan variabel yang diteliti; (3) Menyajikan laporan keuangan dalam mata uang Rupiah; dan (4) Laporan keuangan yang disajikan harus berakhir per 31 Desember. Jumlah sampel yang memenuhi kriteria adalah 110 perusahaan. Metode analisis yang digunakan adalah metode analisis data kuantitatif dan diolah menggunakan program E-views.

Operasionalisasi Variabel Penelitian. Variabel dependen dalam penelitian ini adalah Cash Holdings. Cash holdings merupakan jumlah kas yang tersedia di perusahaan untuk diinvestasikan pada aset fisik dan dibagikan kepada para investor. Cash holding dihitung dengan membagi kas dan setara kas dengan jumlah nilai buku total aset dikurangi kas dan setara kas (Gill and Shah, 2012 dan Ali et al., 2016).

Variabel independen yang pertama dalam penelitian ini adalah komisaris independen. Komisaris independen adalah komisaris yang berasal dari luar perusahaan. Mereka merupakan pihak yang tidak memiliki hubungan dengan direksi maupun pemegang saham (Senjaya dan Yadnyana, 2016). Komisaris independen dihitung dengan persentase komisaris independen terhadap jumlah dewan komisaris dalam perusahaan (Hanani and Muhamad., 2013 dan Basheer, 2014). Komisaris independen dan ukuran dewan direksi diukur dengan skala rasio.

Variabel independen yang kedua dalam penelitian ini adalah ukuran dewan direksi. Menurut (Christian dan Fauziah, 2017), ukuran dewan direksi merupakan jumlah anggota dewan direksi yang ada dalam suatu organisasi. Dalam penelitian ini dewan komisaris diukur dengan skala rasio.

Variabel independen yang ketiga dalam penelitian ini adalah kepemilikan institusional. Kepemilikan institusional berfungsi sebagai pengawas dan pengendali pihak manajemen agar kepentingan shareholders dapat terlindungi (Senjaya dan Yadnyana, 2016). Kepemilikan institusional diukur dengan membagi antara jumlah lembar saham yang dimiliki oleh institusi terhadap jumlah lembar saham perusahaan yang beredar (Senjaya dan Yadnyana, 2016).

Variabel independen yang keempat dalam penelitian ini adalah Capital Expenditure. Capital expenditure merupakan biaya yang dikeluarkan untuk memperbaiki atau menciptakan aset untuk digunakan perusahaan sebagai jaminan. Capital Expenditure dalam penelitian ini dihitung dengan membagi total aset tetap dengan total aset (Enyew, 2016).

Penelitian ini menggunakan analisis regresi liner berganda. Analisis regresi liner berganda dengan data panel dilakukan untuk mendapatkan bukti empiris sejauh mana 
pengaruh komisaris independen, dewan komisaris, kepemilikan institusional dan capital expenditure terhadap cash holding. Menurut (Ajija, 2011), terdapat 3 model yang dapat digunakan untuk menggunakan data panel yaitu: Pooled Least square (PLS), fixed effect, dan random effect.

Yang pertama, Pooled Least square (PLS). Pooled Least square (PLS) sering juga disebut dengan Common Effect. Metode inimengestimasi data panel dengan menggunakan metode Ordinary Least Square (OLS). Pengujian dilakukan tanpa melihat perbedaan waktu (time) dan individu. Pengujian dilakukan dengan menggabungkan data baik time series dan cross section dengan asumsi bahwa perilaku data antar perusahaan adalah sama dalam berbagai kurun waktu. Efek yang sama akan diperoleh walaupun terjadi perubahan terhadap variabel bebas.

Yang kedua, teknik model fixed effect, yaitu teknik yang menambahkan variabel dummy untuk mengizinkan perubahan pada intersep sehingga terjadinya perbedaan antar perusahaan. Hasilnya akan memberikan dampak yang berbeda apabila terjadi perubahan terhadap variabel bebas. Yang ketiga adalah Random Effect. Model ini merupakan variasi dari model Generalized Least Square (GLS dimanamasalah yang ditimbulkan dalam PLS atau Common Effect dapat diperbaiki.

Selanjutnya, untuk menemukan model yang terbaik antara common effect, fixed effect dan random effect, maka digunakan 2 jenis pengujian, yaitu (Ajija, 2011): Uji Chow atau Likehood ratio dan uji Hausman.

Uji Chow bertujuan untuk menentukanmanakah model yang terbaik antara common effect atau fixed effect dengan hipotesis:

$\mathrm{H}_{0}$ : Model common effect

$\mathrm{H}_{1}$ : Model fixed effect

Jika nilai probabilitas signifikansi $\mathrm{F}>0,05$ maka $\mathrm{H}_{0}$ diterima yang berarti model yang terbaik adalah model common effect. Jika $\mathrm{F}<0,05$ maka model yang terbaik adalah fixed effect.

Sedangkan uji Hausman untuk menentukan manakah model yang terbaik antara random effect atau fixed effect dengan hipotesis:

$\mathrm{H}_{0}$ : Model random effect

$\mathrm{H}_{1}$ : Model fixed effect

Untuk mengetahui hipotesis yang dipilih maka perlu dilihat nilai statistik chi square dengan probabilitas $>0,05$ maka $\mathrm{H}_{0}$ diterima. Artinya model yang terbaik adalah random effect. Namun, apabila nilai probabilitas signifikansi $\mathrm{F}<0,05$ maka model terbaik adalah fixed effect.

Hasil Uji Statistik. Hasil pengujian analisis deskriptif untuk masing-masing variabel disajikan pada tabel 1 sebagai berikut:

Tabel 1. Hasil Analisis Statistik Deskriptif

\begin{tabular}{lccccc}
\hline & $\mathrm{Y}$ & $\mathrm{X} 1$ & $\mathrm{X} 2$ & $\mathrm{X} 3$ & $\mathrm{X} 4$ \\
\hline Mean & 0.149345 & 0.406386 & 5.303030 & 0.716803 & 0.362222 \\
Median & 0.055700 & 0.375000 & 5.000000 & 0.751800 & 0.325600 \\
Maximum & 1.713500 & 0.750000 & 16.00000 & 0.994100 & 0.847300 \\
Minimum & 0.000000 & 0.200000 & 2.000000 & 0.322200 & 0.038300 \\
Std. Dev. & 0.224683 & 0.096190 & 2.755319 & 0.160948 & 0.182636 \\
Skewness & 3.226238 & 0.955655 & 1.401173 & -0.153966 & 0.534582 \\
\hline
\end{tabular}


Yanti, Susanto, Wirianata, Viriany: Corporate Governance, Capital Expenditure dan...

\begin{tabular}{lccccc}
\hline Kurtosis & 17.57026 & 3.720503 & 4.939272 & 2.023931 & 2.665932 \\
& & & & & \\
Jarque-Bera & 3491.496 & 57.36811 & 159.6914 & 14.40358 & 17.25229 \\
Probability & 0.000000 & 0.000000 & 0.000000 & 0.000745 & 0.000179 \\
& & & & & \\
Sum & 49.28380 & 134.1073 & 1750.000 & 236.5449 & 119.5333 \\
Sum Sq. Dev. & 16.60868 & 3.044089 & 2497.697 & 8.522551 & 10.97410 \\
Observations & 330 & 330 & 330 & 330 & 330 \\
\hline
\end{tabular}

Sumber: Hasil Uji Statistik dengan E-views.

Untuk hasil uji Chow dapat dilihat pada tabel 2 di bawah ini:

Tabel 2. Hasil uji Chow

\begin{tabular}{lrrr}
\hline \hline Effects Test & Statistic & d.f. & Prob. \\
\hline \hline Cross-section F & $\mathbf{1 1 . 8 0 7 1 7 4}$ & $\mathbf{( 1 0 9 , 2 1 6 )}$ & $\mathbf{0 . 0 0 0 0}$ \\
Cross-section Chi-square & 640.176234 & 109 & 0.0000 \\
\hline \hline
\end{tabular}

Sumber: Hasil Uji Statistik dengan E-views.

Berdasarkan Tabel 2 nilai probabilitas $\mathrm{F}<0.05$, artinya model yang terbaik adalah fixed effect.

Adapun hasil uji Hausman dapat dilihat pada Tabel 3 di bawah ini:

Tabel 3. Hasil Uji Hausman

\begin{tabular}{llrr}
\hline \hline Test Summary & $\begin{array}{l}\text { Chi-Sq. } \\
\text { Statistic }\end{array}$ & Chi-Sq. d.f. & Prob. \\
\hline \hline Cross-section random & 1.085860 & 4 & 0.8965 \\
\hline \hline
\end{tabular}

Sumber: Hasil Uji Statistik dengan E-views

Berdasarkan Tabel 3, probabilitas cross-section random $>0.05$, artinya model penelitian yang terbaik adalah random effect.

Dari hasil uji regresi berganda dapat dilihat pada Tabel 4 di bawah ini:

Tabel 4. Hasil Analisis Regresi Berganda

Dependent Variable: Y 
Method: Panel EGLS (Cross-section random effects)

Date: $12 / 02 / 18$ Time: $18: 49$

Sample: 20142016

Periods included: 3

Cross-sections included: 110

Total panel (balanced) observations: 330

Swamy and Arora estimator of component variances

\begin{tabular}{crrrr}
\hline \hline Variable & Coefficient & Std. Error & t-Statistic & Prob. \\
\hline \hline C & 0.217483 & 0.091810 & 2.368840 & 0.0184 \\
X1 & 0.065340 & 0.108299 & 0.603331 & 0.5467 \\
X2 & 0.008947 & 0.006105 & 1.465521 & 0.1437 \\
X3 & 0.060483 & 0.092312 & 0.655207 & 0.5128 \\
X4 & -0.512089 & 0.078054 & -6.560734 & 0.0000
\end{tabular}

Sumber: Hasil Uji Statistik dengan E-views

Berdasarkan Tabel 4, maka model untuk persamaan regresi ganda yang digunakan dalam penelitian ini dapat dirumuskan sebagai berikut:

$$
\mathrm{Y}=0.217483+0.065340 \mathrm{X} 1+0.008947 \mathrm{X} 2+0.060483 \mathrm{X} 3-0.512089 \mathrm{X} 4+\varepsilon
$$

Keterangan : $\mathrm{Y}=$ Cash Holdings; $\mathrm{X}_{1}=$ Komisaris Independen; $\mathrm{X}_{2}=$ Ukuran Dewan Komisaris; $\mathrm{X}_{3}=$ Kepemilikan Institusional; $\mathrm{X}_{4}=$ Capital Expenditure

Dari hasil uji t, nilai probabilitas untuk variabel komisaris independen adalah sebesar 0,5467 sehingga Ha1 ditolak. Artinya komisaris independen tidak berpengaruh signifikan terhadap cash holding.

Nilai probabilitas untuk variabel ukuran dewan komisaris adalah sebesar 0.1437 , sehingga Ha2 ditolak. Artinya ukuran dewan komisaris tidak berpengaruh signifikan terhadap cash holding. Nilai probabilitas untuk variabel kepemilikan institusional adalah 
sebesar 0,5128, sehingga Ha3 ditolak. Artinya kepemilikan institusional tidak berpengaruh signifikan terhadap cash holding.

Nilai probabilitas untuk capital expenditure adalah sebesar 0,000 dengan nilai koefisien regresi adalah sebesar - 0,512089. Oleh karena itu dapat disimpulkan bahwa Ha4 diterima. Artinya capital expenditure berpengaruh signifikan dan negative terhadap cash holding.

Berikut adalah hasil Uji F dapat dilihat pada Tabel 5 berikut ini:

Tabel 5. Hasil Uji F

\begin{tabular}{llll}
\hline \hline & & & \\
R-squared & 0.124250 & Mean dependent var & 0.042691 \\
Adjusted R-squared & 0.113471 & S.D. dependent var & 0.102142 \\
S.E. of regression & 0.096172 & Sum squared resid & 3.005973 \\
F-statistic & 11.52758 & Durbin-Watson stat & 1.353118 \\
Prob(F-statistic) & $\mathbf{0 . 0 0 0 0 0 0}$ & & \\
\hline \hline
\end{tabular}

Sumber: Hasil Uji Statistik dengan E-views

Berdasarkan Tabel 5, dapat dilihat bahwa nilai probabilitas F statistic adalah 0.0000 atau di bawah 0.05 , artinya model regresi yang digunakan dalam penelitian ini memenuhi goodness of fit.

Hasil uji Koefisien Determinasi dapat dilihat pada Tabel 6 di bawah ini:

Tabel 6. Hasil Uji Koefisien Determinasi

\begin{tabular}{lcll}
\hline \hline & & & \\
R-squared & 0.124250 & Mean dependent var & 0.042691 \\
Adjusted R-squared & $\mathbf{0 . 1 1 3 4 7 1}$ & S.D. dependent var & 0.102142 \\
S.E. of regression & 0.096172 & Sum squared resid & 3.005973 \\
F-statistic & 11.52758 & Durbin-Watson stat & 1.353118 \\
Prob(F-statistic) & 0.000000 & & \\
\hline \hline
\end{tabular}

Sumber: Hasil Uji Statistik dengan E-views

Berdasarkan Tabel 6, diperoleh angka adjusted R-Square sebesar 11,35\%. Artinya persentase sumbangan atas pengaruh variable komisaris independen, ukuran dewan komisaris, kepemilikan institusional, dan Capital Expenditure terhadap cash holdings adalah sebesar $11,35 \%$. Sedangkan sisanya $88,65 \%$ dipengaruhi oleh variable lain yang tidak dimasukkan dalam penelitian ini. 
Pembahasan. Hasil pengujian untuk hipotesis pertama menunjukkan bahwa variable komisaris independen tidak berpengaruh signifikan terhadap cash holding. Hasil penelitian ini didukung oleh (Basheer, 2014) dan (Senjaya dan Yadnyana, 2016), tetapi tidak sejalan dengan penelitian (Wassiuzzaman, 2014); (Rehman dan Wang, 2015); (Rahman dan Muhamad, 2013); dan (Kuan et al., 2011) yang menemukan bahwa board independence berpengaruh signifikan terhadap cash holding.

Menurut (Lee and Lee, 2010), perusahaan dengan jumlah komisaris independen yang banyak akan memiliki cash holdings yang rendah karena komisaris independen dapat mengurangi dominasi dari pihak manajemen untuk menahan kas perusahaan yang dapat memberikan keuntungan kepada mereka. Namun dari hasil penelitian yang tidak signifikan pada penelitian ini menunjukkan bahwa komisaris independen belum berperan optimal dalam mengurangi dominasi dari pihak manajemen untuk menahan kas perusahaan.

Hasil pengujian untuk hipotesis kedua menunjukkan bahwa variable ukuran dewan komisaris tidak berpengaruh signifikan terhadap cash holding. Hasil penelitian ini didukung oleh (Wassiuzzaman, 2014), tetapi berlawanan dengan hasil penelitian yang dilakukan oleh (Christian dan Fauziah, 2017) (Gill dan Shah, 2012); (Senjaya dan Yadnyana, 2016); (Kuan et al., 2012); (Rehman and Wang, 2015); dan (Jamil et al., 2016) yang menunjukkan adanya pengaruh yang signifikan ukuran dewan komisaris terhadap cash holding.

Menurut (Lee and Lee, 2010) perusahaan dengan ukuran dewan komisaris yang kecil diperkirakan memiliki cash holdings yang kecil karena ukuran dewan komisaris yang kecil cenderung lebih efisien dalam pengambilan keputusan. Namun berdasarkan hasil penelitian yang tidak signifikan ini menunjukkan bahwa fungsi dewan komisaris sebagai pengawas terhadap tindakan manajemen belum optimal dalam mengurangi jumlah cash holdings di dalam perusahaan.

Hasil pengujian untuk hipotesis ketiga menunjukkan bahwa kepemilikan institusional tidak berpengaruh signifikan terhadap cash holding. Hal ini sejalan dengan penelitian yang dilakukan oleh (Senjaya dan Yadnyana, 2016), tetapi berlawanan dengan (Christina dan Ekawati, 2016) dan (Harford et al., 2008) yang menemukan bahwa kepemilikan institusional berpengaruh signifikan terhadap cash holding di dalam perusahaan.

Kepemilikan institusional berfungsi sebagai pengawas dan pengendali pihak manajemen agar kepentingan shareholders dapat terlindungi (Senjaya dan Yadnyana, 2016). Transparansi dan kepemilikan institusional berhubungan positif terhadap cash holdings sehingga dengan tingginya tingkat kepemilikan institusional maka tingkat kepemilikan kas akan semakin kecil untuk menghindari excess cash holdings (Christiana dan Ekawati, 2014). Namun hasil penelitian yang tidak signifikan pada penelitian ini menunjukkan bahwa fungsi kepemilikan institusional sebagai pengawas dan pengendali pihak manajemen belum optimal dalam mengurangi jumlah cash holdings di dalam perusahaan.

Hasil pengujian untuk hipotesis keempat menunjukkan bahwa Capital Expenditure berpengaruh signifikan dan negative terhadap cash holding. Hasil penelitian ini sejalan dengan hasil penelitian yang dilakukan oleh (Kim et al., 2011); (Rehman and Wang, 2015); (Wassiuzzaman, 2014); (Enyew A, 2016); dan (Bates et al., 2009); dan (Sutrisno dan Gumanti, 2016), tetapi bertolak belakang dengan penelitian yang dilakukan oleh 
penelitian (Borhanuddin, 2011); dan (Guney, 2006) yang menunjukkan bahwa capital expenditure tidak berpengaruh secara signifikan terhadap cash holding.

\section{PENUTUP}

Hasil penelitian ini dapat disimpulkan sebagai berikut. Pertama, komisaris independen tidak berpengaruh signifikan terhadap cash holding, sehingga Ha1 ditolak. Hasil penelitian ini didukung oleh (Basheer, 2014) dan (Senjaya dan Yadnyana, 2016) yang membuktikan bahwa terdapat pengaruh yang tidak signifikan board independence terhadap cash holding. Sedangkan pada penelitian (Wassiuzzaman, 2014); (Rehman and Wang, 2015); (Rahman dan Muhamad, 2013); dan (Kuan et al., 2011) menemukan bahwa board independence berpengaruh signifikan terhadap cash holding.

Kedua, ukuran dewan komisaris tidak berpengaruh signifikan terhadap cash holding, sehingga Ha2 ditolak. Hasil penelitian ini didukung oleh (Wassiuzzaman., 2014) yang membuktikan bahwa terdapat pengaruh yang tidak signifikan ukuran dewan komisaris terhadap cash holding. Sebaliknya, pada penelitian yang dilakukan oleh (Christian dan Fauziah 2017) (Gill and Shah, 2012); (Senjaya and Yadnyana, 2016); (Kuan et al., 2012); (Rehman and Wang, 2015); dan (Jamil et al., 2016) menunjukkan bahwa ukuran dewan komisaris berpengaruh signifikan terhadap cash holding.

Ketiga, kepemilikan institusional tidak berpengaruh signifikan terhadap cash holding, sehingga Ha3 ditolak. Hal ini sejalan dengan penelitian yang dilakukan oleh (Senjaya dan Yadnyana, 2016). Tetapi penelitian ini tidak sejalan dengan (Christina dan Ekawati, 2016) dan (Harford et al., 2008) yang menemukan bahwa kepemilikan institusional berpengaruh signifikan terhadap cash holding.

Keempat, Capital Expenditure berpengaruh signifikan dan negative terhadap cash holding, sehingga Ha4 diterima. Hasil penelitian ini sejalan dengan hasil penelitian yang dilakukan oleh (Kim et al., 2011); (Rehman and Wang, 2015); (Wassiuzzaman, 2014); (Enyew A., 2016); dan (Bates et al., 2009); dan (Sutrisno dan Gumanti, 2016) yang membuktikan bahwa capital expenditure berpengaruh negative dan signifikan terhadap cash holding. Namun sebaliknya, hasil penelitian ini bertolak belakang dengan penelitian yang dilakukan oleh penelitian (Borhanuddin, 2011); dan (Guney, 2006) yang menunjukkan bahwa capital expenditure tidak berpengaruh secara signifikan terhadap cash holding.

Penelitian ini memiliki beberapa keterbatasan. Pertama, dari hasil uji koefisien determinasi diperoleh angka adjusted R-Square sebesar 11,35\%, artinya persentase sumbangan atas pengaruh variable komisaris independen, ukuran dewan komisaris, kepemilikan institusional, dan Capital Expenditure terhadap cash holdings hanya sebesar $11,35 \%$. Sedangkan sisanya $88,65 \%$ dipengaruhi oleh variable lain yang tidak dimasukkan dalam penelitian ini.

Kedua, terbatasnya jumlah tahun pengamatan yang hanya tiga tahun (2014-2016). Ketiga, sampel perusahaan yang diteliti hanya meliputi sektor manufaktur yang terdaftar di Bursa Efek Indonesia.

Berdasarkan keterbatasan-keterbatasan di atas, maka ada beberapa saran yang dapat diberikan. Pertama, bagi penelitian selanjutnya. Penelitian selanjutnya dapat menambah jumlah variable independen misalnya: Growth Opportunities, Cash Flow, Cash Flow Votality, $R \& D$ Expenditure dan lain sebagainya. 
Kedua, penelitian selanjutnya dapat memperluas periode penelitian yang digunakan dan menggunakan sampel perusahaan yang lebih luas, misalnya menggunakan seluruh sektor perusahaan yang terdaftar di BEI.

Ketiga, bagi perusahaan. Hasil penelitian ini diharapkan dapat memberikan informasi bagi perusahaan mengenai pentingnya perusahaan dalam melakukan pengelolaan kas yang efektif dan efesien dengan memperhatikan faktor-faktor yang mempengaruhi cash holding secara signifikan, dimana dalam penelitian ini adalah variable capital expenditure. Dengan demikian, perusahaan dapat memilih keputusan yang tepat dalam mengelola kas untuk menjaga likuiditas perusahaan sehingga dapat meminimalkan resiko likuiditas yang dapat memicu terjadinya financial distress.

Ketempat, bagi calon investor. Hasil penelitian ini diharapkan dapat memberikan informasi mengenai kondisi perusahaan agar para calon investor dapat menilai likuiditas perusahaan sehingga dapat mengambil keputusan investasi yang tepat.

\section{DAFTAR RUJUKAN}

Ali, S., Mishkat U., \& Nazir U. (2016). Determinants of Corporate Cash Holdings "A Case of Textile Sector in Pakistan. Institute of Business and Management Science, 5(3), 1-10.

Basheer, M. F. (2014). "Impact of Corporate Governance on Corporate Cash Holdings: An Empirical Study of Firms in Manufacturing Industry of Pakistan". Innovative Space of Scientific Research Journals, 7(4), 1371 - 1383.

Bates, T. W., Kathleen M. K., \& Rene M. S. (2009). Why Do US Firms Hold So Much More Cash Than They Used To?. The Journal of Finance, 64(5), 1985-2021.

Borhanuddin, R. I. (2011). Cash Holding, Leverage, Ownership Concentration and Board Independence: Evidence From Malaysia, 10(7), 63-88.

Christian, N \& Fauziah, F. (2017). Faktor-Faktor Penahanan Dana (Cash Holding).Global Financial Accounting Journal, 1(1), 13-24.

Christiana, Y.T. dan Ekawati, E.(2014). "Excess Cash Holdings dan Kepemilikan Institusional pada Perusahaan Manufaktur yang Terdaftar di BEI". Jurnal Manajemen Strategi Bisnis dan Kewirausahaan. 8 (1).1-103.

Enyew, A.M., (2016). "The Factors Affecting Cash Holding Decisions Of Manufacturing Share Companies In Ethiopia", International Journal of Advanced Research in Management and Social Sciences, 5(3), 48-67.

Gill, A. \& Shah, C. (2012). "Determinants of Corporate Cash Holdings: Evidence from Canada". International Journal of Economics and Finance, 4(1), 70-79.

Guney, Y., Ozkan, A. and Ozkan, A. (2006). "International Evidence on The Non-linear Impact of Leverage on Corporate Cash Holdings", Journal of Multinational Financial Management: 1-16.

Hanani, A. dan Muhamad, S.F. (2013). "Corporate Governance and Firms Cash Holding in Malaysia". Proceeding of the International Conference on Social Science Research. Penang. 1236-1247.

Harford, Jarrad, Sattar A. M., \& William F. M., (2008).Corporate Governance and Firm Cash Holdings in the US. Journal of Financial Economics, 87(3), 535-555.

Jamil, Sulaman, Amna A., Naila A., Adnan T., and Mohsin Asif. (2016). Determinants of Corporate Cash Holdings: Empirical Analysis of Pakistani Firms. IOSR Journal of Economics and Finance, 7(3), 29-35. 
Jensen, M.C and Meckling, W.H.(1976). "Theory of the Firm:managerial Behaviour, Agency Costand Ownership Structure”. Journal of Financial Economics.3. 305-360.

Jensen, M. C.(1986). "Agency Cost of Free cash flow, Corporate Finance, and Takeovers. Corporate Finance, and Takeovers". American Economic Review, 76(2), 323-329.

Kim, J., Hyunjoon K., \& David W. (2011). Determinants of Corporate Cash Holding Levels: An Empirical Examination of The Restaurant Industry. International Journal of Hospitality Management, 30(3), 568-574.

Kuan, T.H, Chu S.L, \& Shin H.C. (2011). Cash holdings and Corporate Governance in Family-Controlled Firms. Journal of Business Research, 64, 757-764.

Lee, K.W and Lee, C.F.(2010).Cash Holdings, Corporate Governance Structure and Firm Valuation. Available at: http;//papers.ssrn.com/sol3/paperscfm?abstract_id=1536481

Myers, S.C.(1977). "Determinants of Corporate Borrowing". Journal of Financial Economics. 5. 147-175.

Myers, S.C. and Majluf, N. (1984). "Corporate Financing and Investment Decision When Firms Have Informations that Investors Do Not Have". Journal of Financial Economics. 13. 187-221.

Rahman, A. H. Ab. \& Muhamad, S. F. (2013). "Corporate Governance and Firms Cash Holding In Malaysia". Proceeding of the International Conference on Social Science Research, 1236-1247.

Rehman, A. \& Wang, M. (2015). Corporate Cash Holdings and Adjustment Behaviour in Chinese Firms: An Empirical Analysis using Generalized Method of Moments. Australasian Accounting, Business and finance journal, 9(4), 20-37.

Senjaya, S.Y. \& Yadnyana, I.K. (2016). “Analisis pengaruh Investement OpportunitySet, Cash Conversion Cycle dan Corporate Governance Structure terhadap Cash Holding”. E-Jurnal Ekonomi dan Bisnis Universitas Udayana, 5(8). 2549-2578.

Sutrisno dan Gumanti, (2016). "Pengaruh Krisis Keuangan Global dan Karakteristik Perusahaan Terhadap Cash Holding Perusahaan di Indonesia”. Jurnal Siasat Bisnis. 20(2), 130-142.

Wassiuzzaman, S. (2014). "Analysis of Corporate Cash Holdings of Firms in Malaysia". Journal of Asia Business Studies, 8(2), 118-136. 